\title{
Individual and family correlates for cigarette smoking among Taiwanese college students
}

\author{
Susan Shur-Fen Gau ${ }^{\mathrm{a}, \mathrm{b}, *}$, Meng-Chuan Lai ${ }^{\mathrm{a}}$, Yen-Nan Chiu ${ }^{\mathrm{a}}$, Chun-Te Liu ${ }^{\mathrm{c}}$, \\ Ming-Been Lee ${ }^{\mathrm{a}, \mathrm{b}}$, Hai-Gwo Hwu ${ }^{\mathrm{a}, \mathrm{b}}$ \\ a Department of Psychiatry, National Taiwan University Hospital, Taipei 10002, Taiwan \\ ${ }^{\mathrm{b}}$ Department of Psychiatry, College of Medicine, National Taiwan University, Taipei 10051, Taiwan \\ ${ }^{\mathrm{c}}$ Institute of Management, National Kaohsiung First University of Science and Technology, Kaohsiung 81164, Taiwan
}

\begin{abstract}
Objective: This college-based questionnaire survey aimed to explore the individual, family, and peer correlates for cigarette smoking among first-year college students.

Method: The sample included 2918 first-year college students (males, 45.5\%) recruited from a national university in Taiwan (participation rate, 79.1\%). The participants reported on questions about various substances, attitudes toward substances, personality characteristics, psychopathology, suicidal behaviors, parenting style, family function and use of substances, and peer substance use.

Results: There were 263 (9.0\%; males, 70.6\%) current smokers. Compared to nonsmokers, college smokers were more extraverted and neurotic, and showed less harm avoidance, and more novelty seeking in their personality. They had more hostile, somatic, depressive, paranoid, and psychotic symptoms in terms of psychopathology. Smokers were more likely to use other substances, and to have suicidal ideations, wishes, plans, and attempts. Smokers perceived lower family cohesion, less care from their fathers, and less overprotection from their mothers. They were more likely to have peers and family members who also smoked or used other substances. The most associated correlates were male sex, older age, other substance use, novelty seeking, suicidal ideation and attempts, sibling and peer substance use, a prosubstance attitude, and less maternal overprotection.

Conclusions: Our findings support the association of cigarette use in Taiwanese young adults with several individual, family, and peer factors identified in Western studies. Intervention in cigarette use should be multifaceted, by taking its correlates and the concurrent psychopathology, use of substances, and suicidality into consideration.
\end{abstract}

(C) 2009 Elsevier Inc. All rights reserved.

\section{Introduction}

Tobacco is the most prevalently used substance throughout the world, across different sex and age groups. Currently, there are around 1.3 billion smokers worldwide [1]; and Asia, Australia, and the Far East are the largest tobacco consumers (2715 billion cigarettes per year) [2]. The rates of current smokers were $23.9 \%$ for men and $18.0 \%$ for females in the United States [3], were $25 \%$ for men and $23 \%$ for women in the UK [4], and were $46.5 \%$ in men and $4.2 \%$ in women in Taiwan [5]. The percentage of

* Corresponding author. Department of Psychiatry, National Taiwan University Hospital, Taipei 100, Taiwan. Tel.: +886 2 23123456x66802; fax: +886223812408 .

E-mail address: gaushufe@ntu.edu.tw (S.S.-F. Gau).
Taiwanese male smokers is considerably high compared to those of Western countries; the early age of smoking onset (18-20 years old) [5] is consistent with several reports of young Taiwanese smokers [6,7]. Data from college students in China also demonstrated elevated risk of progression in cigarette use upon entrance into college [8]. From a preventive perspective, this increasing prevalence and early age of onset of tobacco consumption in the Taiwanese population warrants a thorough examination of correlates for these young Taiwanese smokers.

Smokers, regardless of habitual use or abuse/dependence, have been consistently described as more extraverted [9-12] and probably more neurotic in personality $[12,13]$. Moreover, they may tend to be psychopathic [14], impulsive [15], disobedient $[15,16]$, risk-taking $[15,16]$, novelty seeking $[12,17,18]$, and less conscientious [12]. 
Despite the unclear biological mechanism, cigarette smoking does consistently correlate with a variety of mental health problems [19], including depressive disorders [20], depressive symptoms [21], schizophrenia [22,23], anxiety disorders [20] (particularly panic attacks, panic disorder, agoraphobia, and generalized anxiety disorder) [24,25], attention-deficit/hyperactivity disorder [26,27], conduct disorders [26], and the onset of depression [28,29]. Attentiondeficit/hyperactivity disorder and conduct disorder are the most predictive variables for the initiation of smoking [30], regular smoking [27] or nicotine dependence [26]. For college students particularly, depressive symptoms are associated with cigarette smoking in American [31] and also Chinese American [32], and levels of depressive symptoms are positively correlated with daily amounts of cigarette use [33].

Cigarette has long been proposed as a "gateway drug" to other illicit substances, both psychosocially and pharmacologically [34,35], particularly in individuals with attention-deficit/hyperactivity disorder [36]. Numerous studies have demonstrated that cigarette use is related to abuse of other substances (particularly alcohol) in various cultures [26,37-39] and the use of betel nut in Taiwan $[26,39]$.

The association between smoking and suicidal behavior has been clearly demonstrated in several clinic-based [40,41] and large-scale, population-based cohort studies across different populations [42-45]. Moreover, suicidal risk increased linearly with the increasing level of joint use of alcohol, cigarettes, and coffee [46]. However, cigarette smoking in adolescence does not appear to elevate the risk of later suicidal ideation, after taking depression and the parentchild relationship into consideration [47]; a recent national survey in the United States has reported that this association disappears after controlling for mental disorders [48].

Several familial protective factors against cigarette smoking in adolescents and young adults reported in Western [49-52] and Chinese populations [53,54] are intact family structure [49], high level of family attention [50], family cohesion and bonding [55-58], strict home smoking rules [51], and parental monitoring [51]. In contrast, parental $[51,55]$ and sibling $[26,55]$ smoking significantly predicted adolescents' initiation of cigarette use, or current and lifetime smoking, yet the findings of the relationship of parental smoking to adolescent smoking have been less consistent than those of sibling smoking $[26,56]$.

Adolescents whose parents demonstrate authoritative parenting [57,58] and antismoking socialization [59-61], and who have a high quality of communication with them $[59,62]$, particularly on topics related to antismoking [59], are less likely to initiate or maintain cigarette use. In contrast, inadequate parental monitoring predicts adolescent smoking onset [63].

Peer smoking is a strong predictor for the initiation of use, experimentation, and escalation of use, and current use, past use, and maintenance use of cigarettes [64-71]. The probable mechanisms are the pursuit of popularity [72], the selection of friends $[73,74]$, and the conformity of peer identity [64].

Although our previous population-based longitudinal studies have shown an increased prevalence of nicotine use disorder with age [39], and have identified important psychiatric and psychosocial predictors for nicotine use disorder [26] in adolescents, little is known about the individual, familial, and peer factors related to cigarette use among late adolescents and young adults in Taiwan. We, therefore, conducted this study to explore the individual (personality characteristics, psychopathology, use of other substances, suicidal behaviors, and attitude toward substances), family (parenting style, family function, and parent and sibling use of substances), and peer correlates (proportion of peer use substance) of cigarette use among Taiwanese college students, and to identify the most associated correlates for cigarette smoking.

\section{Methods}

\subsection{Participants and procedures}

The participants consisted of 2918 first-year college students (males, $48.5 \%$ ) recruited from the National Taiwan University (NTU; Taipei, Taiwan), an academically leading national university in Taiwan. The Research Ethics Committee of National Taiwan University Hospital approved this study before implementation. In July 2002, a research invitation letter was mailed to each of the newly accepted students by NTU. They were informed that participation in the survey was completely voluntary, and the issue of confidentiality was ensured. Among 3688 new entrants, 2918 (participation rate, 79.1\%) consented to the study and completed the questionnaire in the first week of the fall semester, in conjunction with a routine physical examination upon their entrance to NTU. There was no information about the proportion of eligible subjects who received the letter. The school counselors provided clear instructions on selfadministration before the participants started to fill out the questionnaire. Trained research assistants then checked the completed questionnaires immediately to minimize the missing data.

\subsection{Measures}

The questionnaire contained inquiries about basic demographic data (including age, sex, residential area, mode of entrance to the university, affiliated school and department, living conditions, number of siblings, birth order, and parental age, education, employment status, and marital status) and several instruments (see below).

\subsubsection{Inquiries about substance use}

Questions measuring substance use included regular use (at least once per week) of cigarette, wine/beer, liquor, betel nut, glue, sedatives, and amphetamine. The $\kappa$ statistics for 
test-retest reliability at a 2 -week interval among 115 subjects ranged from 0.67 for regular use of liquor to 1.00 for regular use of betel nuts, glue, sedatives, or amphetamines [75]. A smoker in our study sample was defined as those who reported having a "regular use of cigarette."

\subsubsection{Personality characteristics}

2.2.2.1. Maudsley Personality Inventory, Chinese version. The Maudsley Personality Inventory, a 30-item selfadministered scale, measures 3 personality traits: neuroticism, extraversion, and social desirability. Each item is rated by a "yes" or "no" response. The Chinese Maudsley Personality Inventory, with good reliability and validity, has been administered in both clinical and community settings in Taiwan [65].

\subsubsection{Tridimensional Personality Questionnaire, Chinese} version. The Tridimensional Personality Questionnaire contains 100 items measuring 3 personality dimensions: novelty seeking, harm avoidance, and reward dependence. The reliability and validity of the Chinese Tridimensional Personality Questionnaire have been examined among both adolescent [66,67] and adult samples [68].

\subsubsection{Psychopathology and suicidality}

\subsubsection{Psychopathology: Brief Symptom Rating Scale.}

The Brief Symptom Rating Scale is a 50-item self-reported measurement, with 5 responses for each item: 0 , not at all; 1, a little bit; 2 , moderate; 3 , quite a bit; or 4 , extremely. The BSRS is modified from the Derogatis Symptom Check List-90-Revised covering 9 dimensions of psychopathology: somatization, obsessive-compulsive, interpersonal sensitivity, depression, anxiety, hostility, phobicanxiety, paranoid ideation and psychotic symptoms, and additional symptoms including vegetative signs and suicidal ideation. The General Symptom Index is a mean score of all BSRS categories. The reliability and validity of the BSRS have been demonstrated in a Taiwanese population [69].

2.2.3.2. Inquiries about suicidality. The assessment of suicidality includes inquiries about past and current (past 6 months) wishes to die, suicidal ideations, plans, and attempts.

\subsubsection{Attitudes toward substance use}

Inquiries, using 3 questions, were made into the attitude toward the use of any of the 8 substances. (1) Do you object to the use of any substance among your family members $(1=$ no objection at all, $2=$ less objection, $3=$ more objection, $4=$ strong objection)? (2) If there were an opportunity, would you use any substance $(0=$ definitely not, $1=$ not sure, $2=$ yes)? (3) Do you think the use of the substance is harmful to your health and life $(0=$ no harm, $1=$ mild harm, $2=$ serious harm)? The reliability of the 3 questions has been established elsewhere [26].

\subsubsection{Parenting style and family functioning}

2.2.5.1. Chinese version of the Parental Bonding Instrument. The Parental Bonding Instrument is a 25 -item instrument (items rated on a 4-point Likert scale from "very likely" to "very unlikely") measuring parenting styles during the child's first 16 years, in 3 principle dimensions - care/affection (12 items), overprotection (7 items), and authoritarianism (6 items) [70]. A high score on the care/ affection subscale reflects affection and warmth. Overprotection reflects overprotective parenting and denial of the child's psychological autonomy; authoritarianism reflects the degree of parental authoritarian control over the child's behaviors. This 3-factor structure was found to be better fitted for both Western [71,76] and Asian populations [77]. The reliability and validity of the Chinese Parental Bonding Instrument have been demonstrated elsewhere [78].

2.2.5.2. Chinese Version of the Family Adaptability and Cohesion Evaluation Scale. The Family Adaptability and Cohesion Evaluation Scale III, a 40-item self-reported scale, measures family systems with respect to the levels of current and ideal adaptability and cohesion [79]. Each item is rated on a 5-point Likert scale: 1, almost never; 2, once in a while; 3 , sometimes; 4, frequently; and 5, almost always. In addition to current and ideal conditions, their differences in family cohesion and adaptability are also computed. A high score indicates better family functioning. The reliability and validity of the Chinese Family Adaptability and Cohesion Evaluation Scale III have been described elsewhere [75].

\subsubsection{Peer substance use}

Eight questions were designed to inquire into peer use of the 8 substances. What proportion of your friends has used a substance $(0=$ none, $1=$ less than 1 in 4, $2=$ around half, $3=$ no less than 3 in four, and $4=$ almost all)? The reliability has been examined elsewhere [26].

\subsection{Statistical analysis}

We conducted statistical analysis using SAS 9.1 (SAS Institute Inc, Cary, NC). The preselected $\alpha$ value was at the $P<01$ level. The comparison groups were college students who smoked regularly (smokers) and those who did not (nonsmokers). Linear and nonlinear multilevel models using the MIXED and NLMIXED procedures in SAS were used for the analysis of continuous and binary outcomes, respectively, to control for effects of the lack of independence within the same department, derived from a collegebased sample [80]. The linear multilevel model was used to compare the personality characteristics, psychopathology, family functioning, parenting styles, attitude toward the substances, and peer use of substances of the 2 groups. The nonlinear multilevel model was used to conduct logistic regression by examining the rates of use of other substances. The odds ratios (ORs) and their $95 \%$ confidence 
intervals $(\mathrm{CI})$ were also calculated. These statistical models were controlled for participant age, sex, and residential area to decrease potential confounding effects from these variables. A multivariate logistic regression analysis was performed for the final model fitting to identify the most associated variables for cigarette smoking, using stepwise model selection.

\section{Results}

\subsection{Demographic features}

No significant difference in mean age in years (SD) was noted between the 1414 males (19.3 [2.9]) and 1504 females (19.3 [2.9]). Around two thirds came from northern Taiwan, and more than half of the participants came from Taipei City (37.1\%) and Taipei County (17.4\%). Regarding birth order, $45.0 \%$ were the first born of families with 2 or more children and $7.5 \%$ were the only child in the family.

\subsection{Prevalence rates of cigarette smoking}

There were $263(9.0 \%)$ current smokers $(13.10 \%$ for males and 5.13\% for females) and 2655 (91.0\%) nonsmokers, and a significantly higher proportion of males among the current smokers (70.6\%) than among the nonsmokers (46.3\%; OR, 2.79; 95\% CI, 2.12-3.18). The mean age (SD) of smokers' first use and regular use (at least once per week) of cigarette was 14.3 (4.4) and 18.4 (3.3), respectively.

\subsection{Personality and psychopathology}

Regarding personality features, smokers were significantly more neurotic $\left(\mathrm{F}_{1,2835}=9.10, P=.003\right)$ and extraverted $\left(\mathrm{F}_{1,2835}=4.43, P=.036\right)$, and less sociable $\left(\mathrm{F}_{1,2835}=29.13\right.$, $P<.001)$; and scored higher in novelty seeking $\left(\mathrm{F}_{1,2830}=\right.$ $74.20, P<.001)$ and lower in harm avoidance $\left(\mathrm{F}_{1,2829}=\right.$ 22.87, $P<.001$ ) than nonsmokers (Table 1 ).

Compared to nonsmokers, smokers were significantly more hostile $\left(\mathrm{F}_{1,2831}=41.07, P<.001\right)$, psychotic-prone $\left(\mathrm{F}_{1,2830}=13.46, P<.001\right)$ and paranoid $\left(\mathrm{F}_{1,2832}=4.21, P=\right.$ $.040)$, and had more somatic and depressive symptoms (Table 1). There were no differences between the 2 groups in terms of obsession, interpersonal sensitivity, anxiety, and phobia (Table 1). In general, smokers had greater psychopathology than nonsmokers.

Regarding the attitude toward substance use, smokers had higher scores in "attempting to use a substance" $\left(\mathrm{F}_{1,2829}=\right.$ 386.28, $P<.0001$ ) and lower scores in "objection to substance use" $\left(\mathrm{F}_{1,2829}=127.98, P<.0001\right)$ and "recognizing substance use as harmful to physical health" $\left(\mathrm{F}_{1,2829}=\right.$ 59.13, $P<.0001$ ) (Table 1).

Table 1

Mean scores of individual characteristics by smoking status

\begin{tabular}{|c|c|c|c|c|c|c|}
\hline & \multicolumn{2}{|c|}{ Smoker $(n=263)$} & \multicolumn{2}{|c|}{ Nonsmoker $(\mathrm{n}=2655)$} & \multicolumn{2}{|c|}{ Statistics $^{\mathrm{a}}$} \\
\hline & Mean & SD & Mean & SD & $\mathrm{F}$ & $P$ \\
\hline \multicolumn{7}{|l|}{ Personality } \\
\hline Neuroticism & 11.32 & 6.47 & 10.53 & 6.40 & $\mathrm{~F}_{1,2835}=9.10$ & .003 \\
\hline Extraversion & 15.82 & 5.25 & 15.23 & 5.45 & $\mathrm{~F}_{1,2835}=4.43$ & .036 \\
\hline Social desirability & 3.20 & 2.05 & 3.69 & 2.08 & $\mathrm{~F}_{1,2835}=29.13$ & $<.001$ \\
\hline Novelty seeking & 18.46 & 4.78 & 16.25 & 4.78 & $\mathrm{~F}_{1,2830}=74.20$ & $<.001$ \\
\hline Harm avoidance & 14.37 & 6.83 & 16.60 & 6.89 & $\mathrm{~F}_{1,2829}=22.87$ & $<.001$ \\
\hline Reward dependence & 18.25 & 3.93 & 19.05 & 3.83 & $\mathrm{~F}_{1,2829}=2.13$ & .144 \\
\hline \multicolumn{7}{|l|}{ Psychopathology } \\
\hline Somatization & 0.67 & 0.61 & 0.58 & 0.54 & $\mathrm{~F}_{1,2831}=6.25$ & .013 \\
\hline Obsession & 1.04 & 0.69 & 0.98 & 0.65 & $\mathrm{~F}_{1,2831}=1.01$ & .316 \\
\hline Interpersonal sensitivity & 1.13 & 0.84 & 1.09 & 0.77 & $\mathrm{~F}_{1,2832}=3.41$ & .065 \\
\hline Depression & 0.81 & 0.67 & 0.71 & 0.61 & $\mathrm{~F}_{1,2830}=5.15$ & .023 \\
\hline Anxiety & 0.65 & 0.68 & 0.61 & 0.60 & $\mathrm{~F}_{1,2831}=2.62$ & .106 \\
\hline Hostility & 0.92 & 0.78 & 0.65 & 0.65 & $\mathrm{~F}_{1,2831}=41.07$ & .001 \\
\hline Phobia & 0.58 & 0.67 & 0.63 & 0.63 & $\mathrm{~F}_{1,2831}=0.24$ & .621 \\
\hline Paranoid & 0.82 & 0.73 & 0.73 & 0.65 & $\mathrm{~F}_{1,2832}=4.21$ & .040 \\
\hline Psychoticism & 0.76 & 0.72 & 0.60 & 0.62 & $\mathrm{~F}_{1,2830}=13.46$ & .001 \\
\hline Additional symptoms & 0.71 & 0.68 & 0.60 & 0.58 & $\mathrm{~F}_{1,2831}=8.67$ & .003 \\
\hline GSI & 0.80 & 0.59 & 0.72 & 0.52 & $\mathrm{~F}_{1,2832}=7.51$ & .006 \\
\hline \multicolumn{7}{|l|}{ Attitudes toward substance abuse } \\
\hline Objection to substance (rating: $1-4$ ) & 3.08 & 0.43 & 3.39 & 0.36 & $F_{1,2829}=127.98$ & $<.0001$ \\
\hline Harm of substance (rating: 1-3) & 2.53 & 0.24 & 2.64 & 0.21 & $\mathrm{~F}_{1,2829}=59.13$ & $<.0001$ \\
\hline Substance attempts (rating: $1-3$ ) & 1.60 & 0.29 & 1.29 & 0.22 & $\mathrm{~F}_{1,2829}=386.28$ & $<.0001$ \\
\hline
\end{tabular}

Neuroticism, extraversion, and social desirability are measured by the Maudsley Personality Inventory; novelty seeking, harm avoidance, and reward dependence are measured by the Tridimensional Personality Questionnaire. Psychopathologies were measured by the Brief Symptom Rating Scale. GSI indicates General Symptom Index.

${ }^{\text {a }}$ Controlled by sex and age and within department dependence. 
Table 2

Descriptions of concurrent substance use and suicidality by smoking status

\begin{tabular}{|c|c|c|c|c|c|c|}
\hline & \multicolumn{2}{|c|}{$\begin{array}{c}\text { Smoker } \\
(\mathrm{n}=263)\end{array}$} & \multicolumn{2}{|c|}{$\begin{array}{l}\text { Nonsmoker } \\
(\mathrm{n}=2655)\end{array}$} & \multicolumn{2}{|c|}{ Statistics $^{\mathrm{a}}$} \\
\hline & $\mathrm{n}$ & $\%$ & $\mathrm{n}$ & $\%$ & OR & $95 \% \mathrm{CI}$ \\
\hline \multicolumn{7}{|l|}{ Substance abuse } \\
\hline \multicolumn{7}{|l|}{ Beer, wine } \\
\hline Occasional use & 235 & 89.4 & 1448 & 54.5 & 6.38 & $4.25-9.56$ \\
\hline Regular use & 19 & 7.2 & 61 & 2.3 & 2.55 & $1.44-4.51$ \\
\hline \multicolumn{7}{|l|}{ Liquor } \\
\hline Occasional use & 141 & 53.6 & 327 & 12.3 & 6.30 & $4.76-8.34$ \\
\hline Regular use & 7 & 2.7 & 7 & 0.3 & 7.21 & $2.28-22.74$ \\
\hline Betel nut & 34 & 12.9 & 8 & 0.3 & 31.26 & $13.78-70.90$ \\
\hline Glue & 7 & 2.7 & 4 & 0.2 & 22.71 & $6.11-84.41$ \\
\hline Amphetamine & 3 & 1.2 & 1 & 0.04 & 41.49 & $3.92-439.08$ \\
\hline Sedatives & 7 & 2.7 & 4 & 0.2 & 22.71 & $6.11-84.41$ \\
\hline \multicolumn{7}{|l|}{ Suicidality } \\
\hline Suicidal ideations & 104 & 39.5 & 655 & 24.7 & 2.39 & $1.79-3.17$ \\
\hline Suicidal wishes & 89 & 33.8 & 553 & 20.8 & 2.40 & $1.78-3.23$ \\
\hline Suicidal plans & 39 & 14.8 & 181 & 6.8 & 2.75 & $1.83-4.14$ \\
\hline Suicidal attempts & 10 & 3.8 & 24 & 0.9 & 5.51 & $2.42-12.49$ \\
\hline
\end{tabular}

${ }^{a}$ Controlled by sex and age and with department dependence.

\subsection{Substance use and suicidal behavior}

Table 2 presents the rates, OR, and 95\% CI for reported concurrent substance use and suicidal behavior of smokers and nonsmokers. Apparently, college smokers were more likely than nonsmokers to use other substances, including alcohol, betel nut, glue, amphetamine, and illicit sedatives. The magnitude of the association increased with the increment of illicitness. Smokers started to drink beer or wine (mean age, 14. 1; SD, 4.1) earlier than nonsmokers (mean age, 14.6; SD, 3.8; $\mathrm{F}_{1,1596}=19.29 ; P<.001$ ). However, there was no difference between the 2 groups in the age of first use of liquor, betel nut, glue, and illicit sedative, and in the age of onset of regular use of beer/wine, liquor, and betel nut.

College smokers were more likely than nonsmokers to have past and current suicidal ideations, wishes to die, suicidal plans, and particularly suicidal attempts (Table 2).

\subsection{Family and peer factors}

Parents of smokers were more likely to be separated or divorced than those of nonsmokers $\left(\chi^{2}=21.28, P<.0001\right)$. College smokers, compared to nonsmokers, reported that their fathers showed less affection and care and mothers less overprotection toward them (Table 3). Concerning perceived family functioning, the current and ideal family cohesion was lower in the smokers than in the nonsmokers. However, smokers did not differ from nonsmokers in their reports on family adaptation, differences between current and real family functioning, and dissatisfaction scores in family functioning.

Table 3

Mean score of family and peer correlates by smoking status

\begin{tabular}{|c|c|c|c|c|c|c|}
\hline & \multicolumn{2}{|c|}{ Smoker $(\mathrm{n}=263)$} & \multicolumn{2}{|c|}{ Nonsmoker $(\mathrm{n}=2655)$} & \multicolumn{2}{|c|}{ Statistics $^{\mathrm{a}}$} \\
\hline & Mean & SD & Mean & SD & $\mathrm{F}$ & $P$ \\
\hline \multicolumn{7}{|l|}{ Parental bonding } \\
\hline \multicolumn{7}{|l|}{ Mother's attitude } \\
\hline Affection and care & 24.70 & 6.86 & 25.75 & 6.62 & $\mathrm{~F}_{1,2824}=2.92$ & .088 \\
\hline Overprotection & 6.52 & 4.49 & 7.29 & 4.31 & $\mathrm{~F}_{1,2824}=3.96$ & .047 \\
\hline Authoritarianism control & 4.75 & 4.06 & 5.18 & 4.02 & $\mathrm{~F}_{1,2824}=0.87$ & .352 \\
\hline \multicolumn{7}{|l|}{ Father's attitude } \\
\hline Affection and care & 21.34 & $(7.93)$ & 22.83 & $(7.27)$ & $\mathrm{F}_{1,2760}=4.67$ & .031 \\
\hline Overprotection & 4.77 & $(4.25)$ & 5.30 & $(4.03)$ & $\mathrm{F}_{1,2758}=0.98$ & .323 \\
\hline Authoritarianism control & 4.77 & $(4.51)$ & 4.77 & $(4.00)$ & $F_{1,2758}=0.18$ & .675 \\
\hline \multicolumn{7}{|l|}{ Family function } \\
\hline \multicolumn{7}{|l|}{ Adaptation } \\
\hline Real & 30.03 & 7.64 & 30.73 & 7.46 & $\mathrm{~F}_{1,2833}=1.43$ & .231 \\
\hline Ideal & 37.54 & 6.27 & 38.68 & 5.79 & $\mathrm{~F}_{1,2825}=1.40$ & .237 \\
\hline Difference & 7.53 & 7.07 & 7.94 & 6.72 & $\mathrm{~F}_{1,2825}=0.15$ & .678 \\
\hline \multicolumn{7}{|l|}{ Cohesion } \\
\hline Real & 32.20 & 8.28 & 34.20 & 7.99 & $\mathrm{~F}_{1,2833}=10.22$ & .001 \\
\hline Ideal & 38.89 & 7.14 & 40.62 & 6.41 & $\mathrm{~F}_{1,2825}=7.10$ & .008 \\
\hline Difference & 6.70 & 6.39 & 6.43 & 6.17 & $\mathrm{~F}_{1,2825}=1.80$ & .180 \\
\hline Dissatisfaction & 10.73 & 8.80 & 10.82 & 8.40 & $\mathrm{~F}_{1,2825}=0.95$ & .331 \\
\hline Peer substance use (rating: $1-5$ ) & 1.78 & 0.37 & 1.53 & 0.38 & $\mathrm{~F}_{1,2829}=65.44$ & $<.0001$ \\
\hline Family history of smoking & $\mathrm{n}$ & $\%$ & $\mathrm{n}$ & $\%$ & OR & $95 \% \mathrm{CI}$ \\
\hline Father & 154 & 58.6 & 1077 & 40.6 & 1.21 & $1.06-1.38$ \\
\hline Mother & 18 & 6.8 & 81 & 3.1 & 1.17 & $0.97-1.40$ \\
\hline Siblings & 61 & 23.2 & 154 & 5.3 & 1.52 & $1.31-1.78$ \\
\hline
\end{tabular}

Parental bonding was measured by the Parental Bonding Instrument, with 3 factors generated: affection and care (score $=0-36)$, overprotection $($ score $=0-21)$, and authoritarianism control (score $=0-18)$.

${ }^{a}$ Controlled by sex and age and with department dependence. 
Table 4

Final model of significant psychosocial correlates for tobacco use among college students

\begin{tabular}{lll}
\hline Variables & Odds Ratio & $95 \% \mathrm{CI}$ \\
\hline Sex (male/female) & 2.70 & $1.88-3.84$ \\
Age & 1.12 & $1.08-1.17$ \\
Novelty seeking & 1.07 & $1.04-1.11$ \\
Mothering: overprotection & 0.95 & $0.92-0.99$ \\
Attitude of substance use & & \\
Objection to substance & 0.90 & $0.85-0.96$ \\
Attempts to use substance & 1.48 & $1.34-1.64$ \\
Friends use substances & 1.07 & $1.00-1.13$ \\
Siblings use substances & 1.25 & $1.06-1.49$ \\
Substance use & & $1.31-3.38$ \\
Beer, wine & 2.10 & $1.37-2.79$ \\
Liquor & 1.96 & $3.17-21.09$ \\
Betel nut & 8.17 & $1.56-42.81$ \\
Glue & 8.16 & $1.22-2.42$ \\
Suicidality & & $2.84-20.48$ \\
Current ideations & 1.72 & \\
Ever attempts & 7.63 &
\end{tabular}

Table 3 also summarizes the use of cigarette among family members and the proportion of peers who use substances. Fathers and siblings of the smokers were more likely to smoke than their counterparts. The proportion of friends using substances was higher in college smokers than in nonsmokers $\left(\mathrm{F}_{1,2829}=65.44, P<.0001\right)$ (Table 3$)$.

\subsection{The most associated variables for current cigarette smoking}

In the final fitted model shown in Table 4, the positively associated correlates for cigarette smoking were male sex; older age; novelty-seeking personality characteristics; sibling substance use; peer substance use; attempts to use substances given the opportunity; using other substances including beer, wine, liquor, betel nut, and glue; current suicidal ideations; and ever suicidal attempts. On the other hand, the smokers had less maternal overprotection, and fewer objections to substances than the nonsmokers.

\section{Discussion}

The present large-scale study is one of the few studies simultaneously exploring multiple individual, peer, and familial correlates for college smokers. Most of our findings are compatible with previous individual reports from Western or other Asian populations, along with certain novel findings discussed below. The most significant finding regards the concurrent wide range of individual, family, and peer factors associated with cigarette smoking in Taiwanese college students.

\subsection{Prevalence and demographic features}

The $9.0 \%$ prevalence of current cigarette smoking in our sample is obviously lower than that based on a community- based Taiwanese adult sample [5], as well as those from comparable age-groups in the US [3] and the UK [4] surveys. College male students were more likely than females to smoke, which is consistent with findings from Western studies [81-83], Chinese studies [8,84], and Taiwanese studies as well $[5,26]$. However, the rate for female smokers was comparatively high, which may be due to the more liberal characteristics of our college sample than of the general population in Taiwan.

Corresponding to the findings of increased rates of substance (nicotine) use disorders over grades 7 to 9 among Taiwanese adolescents [39], and the higher rates of smoking in Taiwanese adults [5] than in our young adult sample, our finding indirectly supports the notion of increased rate of smoking with age in late adolescence and young adulthood $[85,86]$.

Consistent with previous Taiwanese studies [6,7], the early mean age of first (14.3 years old) and regular use (18.4 years old) of cigarette implies that young adult smokers started smoking at adolescence. This finding offers support to adolescence as a critical period for the transition of cigarette use [87]. Preventive interventions should be implemented earlier and should focus more on children and adolescents.

\subsection{Personality correlates}

Our findings provide strong evidence supporting the association of smoking in young adults with the personality characteristics of extraversion [9-11], neuroticism [13], impulsiveness and hostility $[14,15]$, and novelty seeking [12,16-18]. Among them, novelty seeking was the only personality characteristic that remained in the final model, suggesting that the effects of other significant personality features related to smoking were largely accounted for by those of novelty seeking and other correlates. The strong association between novelty seeking and smoking has implications for the primary prevention of cigarette smoking $[12,16,18]$. For instance, health education and antismoking practice can focus on attenuating the impulse or curiosity of cigarette experimentation. Surprisingly, our finding showed lower scores in harm avoidance among smokers, suggesting them to be more likely an "optimistic, out-going risk-taker" than their counterparts [88]. This novel finding warrants further exploration.

\subsection{Psychopathology, substance use, and suicidality}

Like other studies, we also found that smoking was associated with depression [21], hostility , paranoia, and psychoticism $[22,23]$. However, the significance of these associations disappeared in the final model, suggesting that the effects of these psychopathologies can be explained by the association between smoking and other factors, particularly concurrent substance use [26,37-39], suicidality [40-45], and novelty seeking [12,16-18]. However, this lack of association may be partially explained by different instruments used. 
In combining several lines of data [37,38] and our results, smoking is strongly correlated with the use of other substances. In addition to the common use of alcohol among smokers [26,39], the unique findings of this study are the increased use of betel nut and glue among Taiwanese college smokers [26]. This partly reflects the pattern of substance use in the Taiwanese population (betel nut as a common "leisure" substance, and the high accessibility to glue).

Our findings lend evidence to support a relationship between suicidality (ideation, wishes, plans, and attempts) and smoking, which has been consistently demonstrated by several large-scale population-based studies from the United States [42], Japan [45], and Finland [43,44]. The significant association with current suicidal ideations and lifetime suicidal attempts cannot be explained by other psychopathological, familial, or peer factors. Accordingly, we strongly recommend that a high level of clinical attention should be directed to college smokers regarding screening and early intervention for suicidal behavior.

\subsection{Attitude toward substance use}

Consistent with Western [89,90] and Taiwanese [26] studies, our findings support the notion that college students viewing substances as harmful to health and having an attitude of objecting to substances protect them from smoking. Our study also supports the association between smoking and attempting substance use whenever there is a chance or the substance is present, which is highly correlated to novelty-seeking personality characteristics [91]. Cognition of and values about substances in childhood and adolescence has preventive implications for the use of cigarette and other substances.

\subsection{Familial and peer influences}

Our results confirm previous reports regarding the association between the subject's smoking and the nonintact family structure [49], parental [51,55] or sibling $[26,55]$ smoking, and less affection and care from the parents [50-52]; they also support the protective role of parental control and monitoring $[51,57,58,63]$. Two interesting findings are that only paternal smoking was associated and that only maternal overprotection remained significantly associated in the final model. These may be related to the ordinal parenting characteristics in Taiwanese families (particularly in those with offspring having high academic achievement, such as the college students recruited in the present study), in which the mothers usually pay more attention to the children and are involved more closely in the children's daily activities than the fathers, until the children's early (even middle) adulthood. Hence, the mothers' overprotective regulation of the children, which is considered a kind of positive parenting in traditional Taiwanese culture [92], may play a vital role in protecting them from cigarette smoking. The greater extent of paternal rather than maternal smoking may demonstrate the modeling effects of the fathers to the smoking children, the allowance of smoking in the families, and the shared genetic liability, and is likely associated with the low base rate of smoking among Taiwanese females [5].

The smoker's less perceived and less ideal cohesion toward his/her family not only corresponds to previous reports [51-54] but indirectly demonstrates the smoker's lower expectation of family cohesion, which possibly reflects both his/her personality characteristics and the family's influences.

Our present findings also lend evidence to support the significant association between peer and sibling smoking and the subjects' current smoking status [55,56,63,93-99] and validate the vital roles of peers and siblings in Taiwanese college students' smoking behavior.

\subsection{Limitations and strength}

There are several limitations to the present study. First, the cross-sectional design limits causal inference. Second, all results were based on self-reported questionnaires instead of face-to-face direct interviews; hence, discrete psychiatric diagnoses were not available. However, self-reported surveys are commonly used in schools to examine students' mental health condition and are generally considered to be valid [100]. Third, findings from this study may not be generalized to other Taiwanese residents beyond those enrolled in the selected university. Fourth, this study is also limited by no assessments of smoking amounts (number of cigarettes per day) and pattern (eg, binge smoking, daily smoking, or situational smoking).

The strength of our study lies in several points. First, it is one of the few studies simultaneously exploring multiple dimensions of individual, peer, family, and psychopathological factors associated with current cigarette smoking. The wealth of reliable and valid self-reported measures provides a holistic and comprehensive picture of the correlates. Second, our study sample was a relatively high-functioning group; the research is thus strengthened by its high response rate and excellent response quality. Third, in terms of the phenomenon that the incidence of cigarette smoking increases significantly in adolescence and young adulthood, the exploration of its correlates in this particular age group provides invaluable information for inferring the etiology and the evolvement of smoking behaviors, and may benefit future research designs. Finally, the present study provides comprehensive information relative to college smokers in the Taiwanese population; hence, it is beneficial to future studies concerning cross-cultural comparisons.

\section{Conclusions}

The present study is one of the few targeting Taiwanese college students' cigarette smoking, which is a serious and growing problem significantly influencing the mental and 
physical health of this population. Our findings, like Western studies, demonstrate the contribution of individual, family, and peer factors to cigarette use in college students and, therefore, imply that cigarette use intervention should be multifaceted, including the manipulation of peer influence, parenting and family smoking, implementation of antismoking cognition, and detection and prevention of psychopathology and other risky behaviors, including substance use and suicidal thoughts and acts.

\section{Acknowledgment}

This work was supported by grants from the National Taiwan University Hospital (NTUH92-S07) and the Office of Student Affairs, National Taiwan University. The manuscript preparation was supported by a grant from the National Health Research Institute (NHRI-EX96-9407PC), Taiwan.

\section{References}

[1] Esson KM, Leeder SR. The Millennium Development Goals and Tobacco Control. 1st ed. Geneva, Switzerland: World Health Organization; 2004.

[2] David A. Building blocks for tobacco control: a handbook. 1st ed. Geneva, Switzerland: World Health Organization; 2004.

[3] Rock V, Malarcher A, Kahende J, Asman K, Husten C, Caraballo R. Cigarette smoking among adults-United States, 2006. Morbidity and mortality weekly report 2007 . cited; available from:http://www. cdc.gov/mmwr/preview/mmwrhtml/mm5644a2.htm.

[4] Office for National Statistics. Cigarette smoking: slight fall in smoking prevalence. cited; available from:http://www.statistics.gov. uk/cci/nugget.asp?id=8662006.

[5] Cheng TY, Wen CP, Tsai MC, Tsai SP. The current status of smoking behavior in Taiwan: data analysis from National Health Interview Survey in 2001. Taiwan J Public Health 2002;22:453-64.

[6] Yen D, Huang SY, Ma AP. A survey on Taiwanese teenager's cognition, attitude, behavioral and psychological characteristics associated with tobacco smoking, alcohol drinking, and betel nut consumption (in Chinese). Taipei: The John Tung Foundation; 1994.

[7] Wu SH, Wu TN. A cohort analysis on tobacco smoking, alcohol drinking, and betel nut consumption in Taiwan: 1994-1997 (in Chinese). Taipei: Department of Health, Executive Yuan; 1998.

[8] Chen X, Li X, Stanton B, Mao R, Sun Z, Zhang H, et al. Patterns of cigarette smoking among students from 19 colleges and universities in Jiangsu Province, China: a latent class analysis. Drug Alcohol Depend 2004;76:153-63.

[9] Eysenck HJ, Tarrant M, Woolf M, England L. Smoking and personality. Br Med J 1960;5184:1456-60.

[10] Rae G. Extraversion, neuroticism and cigarette smoking. Br J Soc Clin Psychol 1975;14:429-30.

[11] Parkes KR. Smoking and the Eysenck personality dimensions: an interactive model. Psychol Med 1984;14:825-34.

[12] Grekin ER, Sher KJ, Wood PK. Personality and substance dependence symptoms: modeling substance-specific traits. Psychol Addict Behav 2006;20:415-24.

[13] Kawakami N, Takai A, Takatsuka N, Shimizu H. Eysenck's personality and tobacco/nicotine dependence in male ever-smokers in Japan. Addict Behav 2000;25:585-91.

[14] McManus IC, Weeks SJ. Smoking, personality and reasons for smoking. Psychol Med 1982;12:349-56.

[15] Geist CR, Herrmann SM. A comparison of the psychological characteristics of smokers, ex-smokers, and nonsmokers. J Clin Psychol 1990;46:102-5.
[16] Burt RD, Dinh KT, Peterson Jr AV, Sarason IG. Predicting adolescent smoking: a prospective study of personality variables. Prev Med 2000;30:115-25.

[17] Kremer I, Bachner-Melman R, Reshef A, Broude L, Nemanov L, Gritsenko I, et al. Association of the serotonin transporter gene with smoking behavior. Am J Psychiatry 2005;162:924-30.

[18] Tercyak KP, Audrain-McGovern J. Personality differences associated with smoking experimentation among adolescents with and without comorbid symptoms of ADHD. Subst Use Misuse 2003;38:1953-70.

[19] Chang G, Sherritt L, Knight JR. Adolescent cigarette smoking and mental health symptoms. J Adolesc Health 2005;36:517-22.

[20] Glassman AH. Cigarette smoking: implications for psychiatric illness. Am J Psychiatry 1993;150:546-53.

[21] Lam TH, Stewart SM, Ho SY, Lai MK, Mak KH, Chau KV, et al. Depressive symptoms and smoking among Hong Kong Chinese adolescents. Addiction 2005;100:1003-11.

[22] de Leon J, Dadvand M, Canuso C, White AO, Stanilla JK, Simpson GM. Schizophrenia and smoking: an epidemiological survey in a state hospital. Am J Psychiatry 1995;152:453-5.

[23] de Leon J, Tracy J, McCann E, McGrory A, Diaz FJ. Schizophrenia and tobacco smoking: a replication study in another US psychiatric hospital. Schizophr Res 2002;56:55-65.

[24] Morissette SB, Tull MT, Gulliver SB, Kamholz BW, Zimering RT. Anxiety, anxiety disorders, tobacco use, and nicotine: a critical review of interrelationships. Psychol Bull 2007;133:245-72.

[25] Breslau N, Klein DF. Smoking and panic attacks: an epidemiologic investigation. Arch Gen Psychiatry 1999;56:1141-7.

[26] Gau SS, Chong MY, Yang P, Yen CF, Liang KY, Cheng AT. Psychiatric and psychosocial predictors of substance use disorders among adolescents: longitudinal study. Br J Psychiatry 2007;190: 42-8.

[27] Kollins SH, McClernon FJ, Fuemmeler BF. Association between smoking and attention-deficit/hyperactivity disorder symptoms in a population-based sample of young adults. Arch Gen Psychiatry 2005; 62:1142-7.

[28] Steuber TL, Danner F. Adolescent smoking and depression: which comes first? Addict Behav 2006;31:133-6.

[29] Klungsoyr O, Nygard JF, Sorensen T, Sandanger I. Cigarette smoking and incidence of first depressive episode: an 11-year, populationbased follow-up study. Am J Epidemiol 2006;163:421-32.

[30] Milberger S, Biederman J, Faraone SV, Chen L, Jones J. ADHD is associated with early initiation of cigarette smoking in children and adolescents. J Am Acad Child Adolesc Psychiatry 1997;36: $37-44$.

[31] Kenney BA, Holahan CJ. Depressive symptoms and cigarette smoking in a college sample. J Am Coll Health 2008;56:409-14.

[32] Tsoh JY, Lam JN, Delucchi KL, Hall SM. Smoking and depression in Chinese Americans. Am J Med Sci 2003;326:187-91.

[33] Lee Ridner S, Staten RR, Danner FW. Smoking and depressive symptoms in a college population. J Sch Nurs 2005;21:229-35.

[34] Fleming R, Leventhal H, Glynn K, Ershler J. The role of cigarettes in the initiation and progression of early substance use. Addict Behav 1989;14:261-72.

[35] Kandel D, Yamaguchi K. From beer to crack: developmental patterns of drug involvement. Am J Public Health 1993;83:851-5.

[36] Biederman J, Monuteaux MC, Mick E, Wilens TE, Fontanella JA, Poetzl KM, et al. Is cigarette smoking a gateway to alcohol and illicit drug use disorders? A study of youths with and without attention deficit hyperactivity disorder. Biol Psychiatry 2006;59: 258-64.

[37] Khan MM, Aklimunnessa K, Kabir MA, Kabir M, Mori M. Tobacco consumption and its association with illicit drug use among men in Bangladesh. Addiction 2006;101:1178-86.

[38] Dierker LC, Sledjeski EM, Botello-Harbaum M, Ramirez RR, Chavez LM, Canino G. Association between psychiatric disorders and smoking stages within a representative clinic sample of Puerto Rican adolescents. Compr Psychiatry 2007;48:237-44. 
[39] Gau SS, Chong MY, Chen TH, Cheng AT. A 3-year panel study of mental disorders among adolescents in Taiwan. Am J Psychiatry 2005;162:1344-50.

[40] Malone KM, Waternaux C, Haas GL, Cooper TB, Li S, Mann JJ. Cigarette smoking, suicidal behavior, and serotonin function in major psychiatric disorders. Am J Psychiatry 2003;160:773-9.

[41] Tanskanen A, Viinamaki H, Hintikka J, Koivumaa-Honkanen HT, Lehtonen J. Smoking and suicidality among psychiatric patients. Am J Psychiatry 1998;155:129-30.

[42] Breslau N, Schultz LR, Johnson EO, Peterson EL, Davis GC. Smoking and the risk of suicidal behavior: a prospective study of a community sample. Arch Gen Psychiatry 2005;62:328-34.

[43] Tanskanen A, Tuomilehto J, Viinamaki H, Vartiainen E, Lehtonen J, Puska P. Smoking and the risk of suicide. Acta Psychiatr Scand 2000; 101:243-5.

[44] Riala K, Alaraisanen A, Taanila A, Hakko H, Timonen M, Rasanen P. Regular daily smoking among 14-year-old adolescents increases the subsequent risk for suicide: the Northern Finland 1966 Birth Cohort Study. J Clin Psychiatry 2007;68:775-80.

[45] Iwasaki M, Akechi T, Uchitomi Y, Tsugane S. Cigarette smoking and completed suicide among middle-aged men: a population-based cohort study in Japan. Ann Epidemiol 2005;15:286-92.

[46] Tanskanen A, Tuomilehto J, Viinamaki H, Vartiainen E, Lehtonen J, Puska P. Joint heavy use of alcohol, cigarettes and coffee and the risk of suicide. Addiction 2000;95:1699-704.

[47] McGee R, Williams S, Nada-Raja S. Is cigarette smoking associated with suicidal ideation among young people? Am J Psychiatry 2005; 162:619-20.

[48] Kessler RC, Berglund PA, Borges G, Castilla-Puentes RC, Glantz MD, Jaeger SA, et al. Smoking and suicidal behaviors in the National Comorbidity Survey: replication. J Nerv Ment Dis 2007;195:369-77.

[49] Griesbach D, Amos A, Currie C. Adolescent smoking and family structure in Europe. Soc Sci Med 2003;56:41-52.

[50] Gosebruch G, Sanchez M, Delva J, Wagner F, Anthony JC. Family attention and tobacco smoking among adolescents in Central America, Panama, and the Dominican Republic. Subst Use Misuse 2003;38:1037-62.

[51] Hill KG, Hawkins JD, Catalano RF, Abbott RD, Guo J. Family influences on the risk of daily smoking initiation. J Adolesc Health 2005;37:202-10.

[52] Duncan TE, Tildesley E, Duncan SC, Hops H. The consistency of family and peer influences on the development of substance use in adolescence. Addiction 1995;90:1647-60.

[53] Shakib S, Zheng H, Johnson CA, Chen X, Sun P, Palmer PH, et al. Family characteristics and smoking among urban and rural adolescents living in China. Prev Med 2005;40:83-91.

[54] Weiss JW, Garbanati JA, Tanjasiri SP, Xie B, Palmer PH. Effects of family functioning and self-image on adolescent smoking initiation among Asian-American subgroups. J Adolesc Health 2006;39: 221-8.

[55] Bricker JB, Peterson Jr AV, Leroux BG, Andersen MR, Rajan KB, Sarason IG. Prospective prediction of children's smoking transitions: role of parents' and older siblings' smoking. Addiction (Abingdon, England) 2006;101:128-36.

[56] Avenevoli S, Merikangas KR. Familial influences on adolescent smoking. Addiction 2003;98(Suppl 1):1-20.

[57] Radziszewska B, Richardson JL, Dent CW, Flay BR. Parenting style and adolescent depressive symptoms, smoking, and academic achievement: ethnic, gender, and SES differences. J Behav Med 1996;19:289-305.

[58] Pierce JP, Distefan JM, Jackson C, White MM, Gilpin EA. Does tobacco marketing undermine the influence of recommended parenting in discouraging adolescents from smoking? Am J Prev Med 2002;23:73-81.

[59] Chassin L, Presson CC, Rose J, Sherman SJ, Davis MJ, Gonzalez JL. Parenting style and smoking-specific parenting practices as predictors of adolescent smoking onset. J Pediatr Psychol 2005;30:333-44.
[60] Andersen MR, Leroux BG, Bricker JB, Rajan KB, Peterson Jr AV. Antismoking parenting practices are associated with reduced rates of adolescent smoking. Arch Pediatr Adolesc Med 2004;158:348-52.

[61] Huver RM, Engels RC, de Vries H. Are anti-smoking parenting practices related to adolescent smoking cognitions and behavior? Health Educ Res 2006;21:66-77.

[62] Otten R, Harakeh Z, Vermulst AA, Van den Eijnden RJ, Engels RC. Frequency and quality of parental communication as antecedents of adolescent smoking cognitions and smoking onset. Psychol Addict Behav 2007;21:1-12.

[63] Biglan A, Duncan TE, Ary DV, Smolkowski K. Peer and parental influences on adolescent tobacco use. J Behav Med 1995;18:315-30.

[64] Stewart-Knox BJ, Sittlington J, Rugkasa J, Harrisson S, Treacy M, Abaunza PS. Smoking and peer groups: results from a longitudinal qualitative study of young people in Northern Ireland. Br J Soc Psychol 2005;44:397-414.

[65] Liao SC, Lee MB, Lee YJ, Weng T, Shih FY, Ma MH. Association of psychological distress with psychological factors in rescue workers within two months after a major earthquake. Taiwan Yi Xue Hui Za Zhi 2002;101:169-76.

[66] Kuo PH, Chih YC, Soong WT, Yang HJ, Chen WJ. Assessing personality features and their relations with behavioral problems in adolescents: Tridimensional Personality Questionnaire and Junior Eysenck Personality Questionnaire. Compr Psychiatry 2004;45: 20-8.

[67] Kuo PH, Yang HJ, Soong WT, Chen WJ. Substance use among adolescents in Taiwan: associated personality traits, incompetence, and behavioral/emotional problems. Drug Alcohol Depend 2002;67: 27-39.

[68] Chen WJ, Chen HM, Chen CC, Chen CC, Yu WY, Cheng AT. Cloninger's Tridimensional Personality Questionnaire: psychometric properties and construct validity in Taiwanese adults. Compr Psychiatry 2002;43:158-66.

[69] Lee MB, Liao SC, Lee YJ, Wu CH, Tseng MC, Gau SF, et al. Development and verification of validity and reliability of a short screening instrument to identify psychiatric morbidity. Taiwan Yi Xue Hui Za Zhi 2003;102:687-94

[70] Cox BJ, Enns MW, Clara IP. The Parental Bonding Instrument: confirmatory evidence for a three-factor model in a psychiatric clinical sample and in the National Comorbidity Survey. Soc Psychiatry Psychiatr Epidemiol 2000;35:353-7.

[71] Lizardi H, Klein DN. Evidence of increased sensitivity using a threefactor version of the Parental Bonding Instrument. J Nerv Ment Dis 2002;190:619-23

[72] Turner K, West P, Gordon J, Young R, Sweeting H. Could the peer group explain school differences in pupil smoking rates? An exploratory study. Soc Sci Med 2006;62:2513-25.

[73] Arnett JJ. The myth of peer influence in adolescent smoking initiation. Health Educ Behav 2007;34:594-607.

[74] de Vries H, Candel M, Engels R, Mercken L. Challenges to the peer influence paradigm: results for 12-13 year olds from six European countries from the European Smoking Prevention Framework Approach study. Tob Control 2006;15:83-8.

[75] Gau SS, Chen YY, Tsai FR, Lee MB, Soong WT, Hwu HG, et al. Risk factors for suicide in Taiwanese college students. J Am Coll Health 2008;57:135-42.

[76] Heider D, Matschinger H, Bernert S, Vilagut G, Martinez-Alonso M, Dietrich S, et al. Empirical evidence for an invariant three-factor structure of the Parental Bonding Instrument in six European countries. Psychiatry Res 2005;135:237-47.

[77] Sato T, Narita T, Hirano S, Kusunoki K, Sakado K, Uehara T. Confirmatory factor analysis of the Parental Bonding Instrument in a Japanese population. Psychol Med 1999;29:127-33.

[78] Gau SS, Shen HY, Chou MC, Tang CS, Chiu YN, Gau CS Determinants of adherence to methylphenidate and the impact of poor adherence on maternal and family measures. J Child Adolesc Psychopharmacol 2006;16:286-97. 
[79] Olson DH. Circumplex Model VII: validation studies and FACES III. Fam Process 1986;25:337-51.

[80] Singer JD. Using SAS PROC MIXED to fit multilevel models, hierarchical models, and individual growth models. J Educ Behav Stat 1998;23:323-55.

[81] Phillips AN, Wannamethee SG, Walker M, Thomson A, Smith GD. Life expectancy in men who have never smoked and those who have smoked continuously: 15 year follow up of large cohort of middle aged British men. BMJ 1996;313:907-8.

[82] Patton GC, Carlin JB, Coffey C, Wolfe R, Hibbert M, Bowes G. The course of early smoking: a population-based cohort study over three years. Addiction 1998;93:1251-60.

[83] Substance Abuse and Mental Health Services Administration OoAS. National Household Survey on drug abuse: population estimates 1997. Rockville (Md): U.S. Department of Health and Human Services; 1998.

[84] Mao R, Li X, Stanton B, Wang J, Hong Y, Zhang H, et al. Psychosocial correlates of cigarette smoking among college students in China. Health Educ Res 2008 Feb 16 [Epub ahead of print].

[85] Simons-Morton BG, Haynie DL. Psychosocial predictors of increased smoking stage among sixth graders. Am J Health Behav 2003;27: 592-602.

[86] Kenford SL, Wetter DW, Welsch SK, Smith SS, Fiore MC, Baker TB. Progression of college-age cigarette samplers: what influences outcome. Addict Behav 2005;30:285-94.

[87] Department of Healthand Human Services US. The health benefit of smoking cessation: a report of the Surgeon General. Atlanta (Ga): Center for Disease Control, Office on Smoking and Health; 1990 [Report No.: DHHS Publication No. (CDC) 90-8416].

[88] Cloninger CR. A systematic method for clinical description and classification of personality variants. A proposal. Arch Gen Psychiatry 1987;44:573-88.

[89] Banks MH, Bewley BR, Bland JM. Adolescent attitudes to smoking: their influence on behaviour. Int J Health Educ 1981;24:39-44.
[90] van Zundert RM, van de Ven MO, Engels RC, Otten R, van den Eijnden RJ. The role of smoking-cessation-specific parenting in adolescent smoking-specific cognitions and readiness to quit. J Child Psychol Psychiatry 2007;48:202-9.

[91] Gerra G, Angioni L, Zaimovic A, Moi G, Bussandri M, Bertacca S, et al. Substance use among high-school students: relationships with temperament, personality traits, and parental care perception. Subst Use Misuse 2004;39:345-67.

[92] Gau SS. Parental and family factors for attention-deficit hyperactivity disorder in Taiwanese children. Aust N Z J Psychiatry 2007;41: 688-96.

[93] Lo SK, Blaze-Temple D, Binns CW, Ovenden C. Adolescent cigarette consumption: the influence of attitudes and peer drug use. Int J Addict 1993;28:1515-30.

[94] West P, Sweeting H, Ecob R. Family and friends' influences on the uptake of regular smoking from mid-adolescence to early adulthood. Addiction 1999;94:1397-411.

[95] Alexander C, Piazza M, Mekos D, Valente T. Peers, schools, and adolescent cigarette smoking. J Adolesc Health 2001;29:22-30.

[96] Vink JM, Willemsen G, Boomsma DI. The association of current smoking behavior with the smoking behavior of parents, siblings, friends and spouses. Addiction 2003;98:923-31.

[97] Kobus K. Peers and adolescent smoking. Addiction 2003;98(Suppl 1):37-55.

[98] Molyneux A, Lewis S, Antoniak M, Browne W, McNeill A, Godfrey $\mathrm{C}$, et al. Prospective study of the effect of exposure to other smokers in high school tutor groups on the risk of incident smoking in adolescence. Am J Epidemiol 2004;159:127-32.

[99] Bricker JB, Peterson Jr AV, Andersen MR, Rajan KB, Leroux BG, Sarason IG. Childhood friends who smoke: do they influence adolescents to make smoking transitions? Addict Behav 2006;31: 889-900.

[100] Gau SF, Soong WT. The transition of sleep-wake patterns in early adolescence. Sleep 2003;26:449-54. 